\title{
Accounting Harmonization Case And Debate
}

Obeua S. Persons, (Email: persons@rider.edu), Rider University

\begin{abstract}
This case/debate is appropriate for an international accounting class at either undergraduate or graduate level. It is also suitable for any upper-level accounting classes which cover a topic of international accounting. This case/debate has been used in a graduate international accounting course over the past three semesters. One evidence of its success is that "Instructor Notes: Discussion of Case Answers" is based upon students' answers. Conversation with students also indicates that they like this classroom technique because it adds diversity to their learning experience. Students also rated this course more favorably in the semesters when the case/debate was used comparing to previous semesters.
\end{abstract}

Accounting harmonization has been a very important issue and is highly debatable in terms of how the harmonization should take shape in the U.S. The first part of "Accounting Harmonization" requires students to answer case requirements in writing. The second part is a debate among four student groups. To encourage active participation of each student in a debate group, a class size should not be larger than 30. This case/debate promotes a number of important skills including analytical, research, writing, oral communication, interpersonal, and teamwork. It also helps students develop negotiation skill by requiring them to take a perspective of another group other than their own preference. Below is the case/debate.

\section{INTRODUCTION}

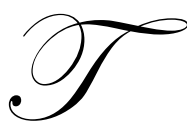

here has been the move towards accounting harmonization/convergence around the world. Which of the following reporting frameworks you believe to be the most suitable for financial reporting by U.S. companies five years from now? To answer this question, students must analyze in writing the strengths and the weaknesses of each framework and provide justification for their preferred framework.

1. U.S. generally accepted accounting principles (GAAP) only.

2. IAS (International Accounting Standards, now known as International Financial Reporting Standards, IFRS) only.

3. Allow U.S. firms to prepare financial statements using either U.S. GAAP or IAS.

4. Combined U.S. GAAP and IAS standards. Provide suggestions on how to best combine U.S. GAAP and IAS.

To help students complete the case, the instructor provides students an article "Why Not Allow FASB and IASB Standards to Compete in the U.S.?" by R.A. Dye and S. Sunder. Accounting Horizon. Vol. 15, No. 3, September 2001, p. 257-271. In addition, students are required to research the following websites: www.iasb.org, www.fasb.org, www.sec.gov. Students are also encouraged to search ABI Inform database for relevant articles.

Students are required to email an instructor their choice of preferred reporting framework a few days before the class when the debate will take place. They do not need to include any discussion other than their specific choice. An instructor then divides students into four debate groups: choice \#1, choice \#2, choice \#3 and choice \#4 groups. To promote negotiation skill, an instructor may want to assign students to a group other than their preferred choice. An 
instructor may also want to caution students that they may not be assigned to the group of their choice. The group assignment is announced in class right before the debate. Guideline for the debate is as follows.

1. $\quad$ Each group has 10-15 minutes to prepare for the debate.

2. Each group has another 10 minutes to present to the class the strengths of its choice and weaknesses of the other three choices.

3. Each group then has five minutes to accept or reject the weaknesses of its own choice stated by the other groups.

4. After the debate ends, each student decides (again) which reporting framework he/she believes to be the most suitable for financial reporting by U.S. companies five years from now.

Total time for the whole debate process is 1.5-2.0 hours. If a class period lasts only 1-1.5 hours, an instructor should inform students about their group assignments a few days before class so that they could use out-of-class time to prepare for the debate. An instructor may also want to reduce the time for items 2 and 3. Students' answers including strengths and weaknesses of the four reporting frameworks and the justification for their choice are collected at the end of class.

\section{INSTRUCTOR NOTES: DISCUSSION OF CASE ANSWERS}

\section{Strengths - U.S. GAAP Only}

1. U.S. GAAP is one of the highest quality and most comprehensive set of standards in the world with worldwide reputation for visionary leadership in standard setting. Switching to another set of standards would lower the quality of financial reports.

2. Investors and analysts are already familiar with the current standards. Changing to another reporting framework would require investors and analysts to spend time and money to learn a new set of standards.

3. Using another reporting framework might increase the opportunities for earnings management through creative accounting as IAS allows more alternative treatments.

4. If more than one set of standards are allowed, the standard setting bodies will compete for not only funding but also the favor from companies to use their standards. This, in turn, could reduce the standards quality as companies choose lax standards over more rigid ones.

5. Financial Accounting Standards Board (FASB), which sets U.S. GAAP, has a transparent due process subject to the public scrutiny.

6. FASB is highly responsive to its constituents including both the investing public and the business community.

7. U.S. GAAP reflects the culture and business environment in which U.S. firms operate.

8. U.S. GAAP requires greater disclosures than any other GAAP.

9. Because FASB has tried to achieve accounting harmonization by reducing some differences between U.S. GAAP and IAS, there is no need for U.S. to switch to another reporting framework.

\section{Weaknesses - U.S. GAAP Only}

1. U.S. GAAP is rule-based with many details which are difficult to understand by investors without accounting expertise.

2. Regardless of its thoroughness rule-based features, companies can still manage earnings within the guidelines of the standards

3. Rule-based standards may prevent firms from selecting accounting policies that accurately convey the economic substance of their transactions.

4. More countries have accepted or will soon accept IAS. Would U.S. companies be excluded from other capital markets because we do not accept IAS? Will we lose foreign investors because we do not use IAS and the rest of the world does?

5. A single set of standards does not allow firms to "vote with their feet". 
6. Special interest groups can influence politicians to exert undue pressure over FASB. An obvious example is the accounting for employee stock options.

\section{Strengths - IAS (Now Known As IFRS) Only}

1. IAS are principle-based standards which allow firms to select accounting treatments that best reflect economic substance of their transactions/situations.

2. There would be greater comparability with the rest of the world as more countries are accepting IAS. In particular, the European Union and Australia have required their publicly-listed companies to use IAS for preparing financial statements since January 2005.

3. Using IAS would make U.S. capital markets more attractive to international investors and foreign companies.

4. U.S. companies would not have to convert from U.S. GAAP to IAS for listing in countries which accept IAS but not U.S. GAAP.

5. It would be harder for special interest groups to put undue pressure on the International Accounting Standards Board (IASB) which sets IAS.

\section{Weaknesses - IAS (Now Known As IFRS) Only}

1. Switching to IAS could reduce the quality of financial reports because it has more alternative accounting treatments which impede comparability and provide more opportunities for earnings management.

2. Less disclosure requirements under IAS than U.S. GAAP could deprive U.S. investors of useful information.

3. U.S. investors and accountants would have to invest time and money to learn IAS.

4. IAS is developed for a very diverse group of companies across different countries, which does not necessarily reflect U.S. culture and business environment. Therefore, IAS may not be appropriate for U.S. firms.

5. IASB has no power to enforce its standards. If a country, such as U.S., disapproves a specific IAS standard (e.g. IAS\#16 - Basis of Property, Plant and Equipment which allows either fair market value or historical cost), this would greatly undermine the acceptability and integrity of IAS.

6.

\section{Strengths - Allow U.S. Firms To Prepare Financial Statements Using Either U.S. GAAP Or IAS}

1. The competitive environment would motivate FASB and IASB to create a better set of standards. This concept is based on the fact that the U.S. SEC will not tolerate low-quality standards and that competition in a market creates a better product.

2. U.S. companies would be able to choose the standards that best capture the economic substance of their operations. This is especially true for companies which list their securities in foreign capital markets and have extensive operations overseas where IAS may be more appropriate than U.S. GAAP.

3. It would make U.S. capital market more attractive to foreign companies because they do not have to incur additional costs of producing U.S. GAAP financial statements or reconciling IAS to U.S. GAAP.

4. It is harder for special interest groups to place undue influence thru political pressure over both standard setting bodies.

5. It allows firms to "vote with their feet", therefore, eliminating the deficient standards and curtailing insufficient and excessive standard setting.

6. A company's choice of accounting standards could serve as an additional signal for analysts/investors to assess the quality of its management and financial reports.

7. Standard setters would be more responsive to business's needs as they cannot set standards which alienate the business community. 


\section{Weaknesses - Allow U.S. Firms To Prepare Financial Statements Using Either U.S. GAAP Or IAS}

1. It undermines the comparability and reliability of financial reports.

2. Investors would bear the burden of trying to understand not only U.S. GAAP but also IAS.

3. It would cause the quality of standards to decline because firms will likely choose standards that produce more favorable earnings and financial position, and standard setters cannot alienate firms since firms can "vote with their feet".

4. Experimentation of having two sets of standards would possibly throw our capital market into a tail spin, and the costs of the upheaval would outweigh any potential benefits the competition might provide.

5. Competition between standard setters to attract client firms will make them more susceptible to lobbying pressure.

\section{Strengths - Combined U.S. GAAP And IAS Standards}

1. As our economy has become a global economy, a combined FASB and IAS would allow for better communication among investors of all nationalities. Accounting would be more organized on a global level rather than a national level.

2. The best of both standards could be combined, therefore, creating higher-quality standards which lead to higher-quality financial reporting.

3. The combined standards would be less rule-based (more principle-based) than the current U.S. GAAP. Such standards would be more suitable to the increasingly more complex business transactions and the accelerating pace of globalization.

4. Combining the two standards would greatly enhance accounting harmonization without ignoring the influence of local U.S. business environment and culture.

5. U.S. investors would not have to learn a completely new set of standards and the combined standards may be easier to understand than the current rule-based U.S. GAAP.

6. The standard setting process might be less susceptible to political pressure from special interest groups because it is harder for them to influence IASB than FASB.

7. The FASB current efforts to achieve accounting harmonization/convergence by reducing specific differences between U.S. GAAP and IAS serves as a supporting evidence for combining U.S. GAAP and IAS.

\section{Weaknesses - Combined U.S. GAAP And IAS Standards}

1. It might be hard and subjective to identify what the best of both standards are.

2. The time to develop a complete set of combined standards may take longer than five years from now.

3. The combined standards may be more lax due to more principle-based nature of IAS which allows more management's discretion and judgement. Consequently, there may be more opportunities for earnings management.

4. U.S. companies will still have to reconcile its financial statements for listing their securities in countries that do not accept U.S. GAAP but accept IAS.

5. The combined standards may be less responsive to U.S. business culture and environment.

6. There are costs involved in developing the combined standards and U.S. investors and firms will have to learn the standards that are combined.

\section{HOW TO BEST COMBINE THE TWO STANDARDS}

A committee composed of representatives from U.S. multinational corporations, accounting firms, institutional investors and creditors, and accounting academia would review both sets of standards for their strengths and weaknesses. The committee will then select the best of both standards and develop an exposure draft of the combined standards. The exposure draft will be subject to the public scrutiny and comments. The committee will then incorporate the comments into the final set of combined standards. It's crucial to rely on a committee which is independent from both FASB and IASB since it will be more impartial and do not favor one set of standards over the other. 
On the other hand, some students might consider the "Norwalk Agreement" between FASB and IASB in October 2002 as the first step toward combining the two standards. Per this agreement, FASB and IASB formally commit to the convergence of U.S. GAAP and IAS. Since then, the FASB has undertaken the following six key initiatives to further the goal of convergence.

1. Joint project being conducted with the IASB to address revenue recognition and business combination.

2. Short-term convergence projects which involves both the FASB and IASB comparing existing standards and conforming the two sets of standards to the higher-quality solution. FASB has issued four exposure drafts as a result of these projects.

a. Voluntary changes in accounting policies (retroactive instead of cumulative application).

b. $\quad$ Three changes to the calculation of earnings per share.

c. Gain or loss must be recognized on the exchange of similar assets.

d. Unusual (abnormal) amount of idle capacity and spoilage costs would be excluded from inventory cost and expensed as incurred.

3. Liaison IASB member on site at the FASB office.

4. $\quad$ FASB monitoring of IASB projects.

5. The convergence research project to identify all substantive differences between U.S. GAAP and IAS.

6. Explicit consideration of convergence potential in all board agenda decisions.

\section{REPORTING FRAMEWORK PREFERRED BY STUDENTS}

Out of 35 students over the past three semesters, 16 students (45.71\%) preferred U.S. GAAP, one student (2.86\%) preferred IAS, ten students $(28.57 \%)$ preferred allowing either U.S. GAAP or IAS, and eight students (22.86\%) preferred combined U.S. GAAP and IAS. Students were assigned to a debate group other than their preferred choice. After the debate, four students changed their preferred choice to combined U.S. GAAP and IAS. The main justification for U.S. GAAP is that U.S. GAAP is already high quality standards acceptable in many international capital markets. To change to another reporting framework would compromise the quality of U.S. financial reporting. Justification for IAS is that it has worldwide acceptability and IASB is the leader of accounting harmonization. Using IAS would greatly enhance the harmonization and the comparability of U.S. financial reporting with the rest of the world. Justification for allowing either U.S. GAAP or IAS is that U.S. firms can choose the reporting framework which best captures the economic substance of their operations. Large corporations with extensive international operations may choose IAS whereas smaller firms or those that prefer locally developed standards may choose U.S. GAAP. Justification for combined U.S. GAAP and IAS is that it will possess the best of both rule-based and principle-based standards which will make U.S. capital markets more attractive to foreign firms for listing their securities. 
NOTES 